This is the final peer-reviewed accepted manuscript of:

Farabegoli, F., Pirini, M., Rotolo, M., Silvi, M., Testi, S., Ghidini, S., Zanardi, E., Remondini, D., Bonaldo, A., Parma, L., Badiani, A., 2018. Toward the Authentication of European Sea Bass Origin through a Combination of Biometric Measurements and Multiple Analytical Techniques. J. Agric. Food Chem. 66, 6822-6831.

The final published version is available online at: https://doi.org/10.1021/acs.jafc.8b00505

Rights / License:

The terms and conditions for the reuse of this version of the manuscript are specified in the publishing policy. For all terms of use and more information see the publisher's website.

This item was downloaded from IRIS Università di Bologna (https://cris.unibo.it/)

When citing, please refer to the published version. 


\title{
Toward the Authentication of European Sea Bass Origin through a Combination of Biometric Measurements and Multiple Analytical Techniques
}

\author{
Federica Farabegoli†*, Maurizio Pirini†, Magda Rotolo†, Marina Silvi†, Silvia Testi†, Sergio

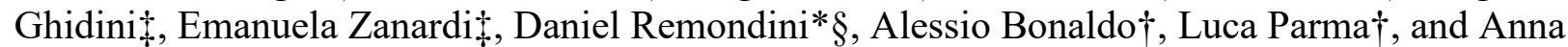 \\ Badiani $\dagger$
}

$\dagger$ Department of Veterinary Medical Science (DIMEVET), University of Bologna, Via Tolara di Sopra 50, 40064 Ozzano dell'Emilia, Bologna, Italy

†Department of Food Science, University of Parma, Via del Taglio 10, 43126 Parma, Italy

$\S$ Department of Physics and Astronomy (DIFA), University of Bologna, Viale Berti Pichat 6/2, 40127 Bologna, Bologna, Italy

\begin{abstract}
The authenticity of fish products has becom an imperative issue for authorities involved in the protection of consumers against fraudulent practices and market stabilization. The present study aimed to provide a method for authentication of European sea bass (Dicentrarchus labrax) according to the requirements for seafood labels (Regulation 1379/ 2013/EU). Data on biometric traits, fatty acid profile, elemental composition, and isotopic abundance of wild and reared (intensively, semi-intensively, and extensively) specimens from 18 southern European sources $(\mathrm{n}=160)$ were collected, clustered in six sets of parameters, and then subjected to multivariate analysis. Correct allocations of subjects according to their production method, origin, and stocking density were demonstrated with good approximation rates $(94,92$, and $92 \%$, respectively) using fatty acid profiles. Less satisfying results were obtained using isotopic abundance, biometric traits, and elemental composition. The multivariate analysis also revealed that extensively reared subjects cannot be analytically discriminated from wild subjects.
\end{abstract}

KEYWORDS: seafood labeling, Dicentrarchus labrax, sea bass authentication, analytical fingerprinting, stocking density, fatty acid profile, isotope analysis, elemental composition

\section{Introduction}

The demand for sea products for human consumption is in continuous expansion, with aquaculture gaining importance in compensating for the deficit of global capture fisheries; (1) as a result, an increasing number of new farmed species have entered the marketplace over the past decade. Public interest in food quality and origin, in particular, the awareness of health benefits derived from fish consumption, has strongly increased in recent years. Differentiation of seafood products may influence consumer preferences, especially concerning discrimination between wild and farmed fish. Actually, consumer choice between wild and reared products seems to be strongly affected by beliefs resulting from stereotypes; for instance, cultured fish are usually associated with the use of antibiotics and growth promoters, while wild products are considered tastier and healthier than reared fish. (2) Thus, regulatory interventions aim to avoid mislabeling or substituting wild fish with farmed specimens and to mitigate risks to consumer confidence and health. In the European context, as a result of the variety of sources of fish products (from seawater or freshwater; from intensive, semi-intensive, or extensive rearing), Regulation (EU) 1379/2013 (3) was issued to give consumers clear and accurate information on the main features and traceability 
of fish products. Because wild fish are generally put on the market at a higher price, there may be a temptation to falsely label farmed products to sell them at a better price. The removal of specific external traits during product processing makes the identification of fish species difficult, and the risk of fraudulent substitution of sought-after species with less valuable species grows. Accidental or intentional mislabeling may also occur due to the global production of seafood, which allows the supply of the same products from different areas 4. Moreover, strong competition among the main producing countries in the Mediterranean region (Italy, Greece, Spain, and Turkey, above all) demands detailed characterization and differentiation of sea bass quality. (5) Verifying the authenticity of fish products is therefore imperative, to check correspondence with the label, establish the real commercial value, avoid unfair competition, and ensure consumer protection against fraudulent practices.

European sea bass (Dicentrarchus labrax) represents one of the main aquaculture fish products in the European Union (EU). (6) European sea bass is a demersal opportunistic species, inhabiting coastal waters (down to about $100 \mathrm{~m}$ depth) and shallow waters, such as estuaries, lagoons, and tidal flats. European sea bass is intensively farmed in floating cages or in inshore ponds and reared semi-intensively or extensively in brackish lagoons. (7) The different rearing systems and feeding regimes in sea bass farming may affect flesh quality, especially in terms of fat level and composition, $\underline{(8)}$ which necessarily influences the quality of the product. $(9,10)$ Wild sea bass feed in inshore and estuarine waters, which offer dietary fatty acids (FAs) from the fauna of those areas, whereas commercial feeds contain quite different FAs, typically fish products obtained from the open oceans. (4) The lipid content of the flesh also influences the ratios of the stable isotopes of carbon $(\mathrm{C})$ and nitrogen $(\mathrm{N})$; the former varies according to the nature of the dietary $\mathrm{C}$ sources as well, while the latter depends upon the trophic position of the diet of the subjects. (11) According to some authors, the employment of chemometric techniques, in support to a documental routine, would be a useful tool to improve transparency and the trust of consumers in the food trade. To date, the most promising approach to characterize a fish product seems to be the application of different analytical techniques on the same matrix, followed by multivariate analysis of the data obtained. (12) The multivariate analysis applied to the FA profiles, obtained using gas chromatography, $(4,10,12,13)$ nuclear magnetic resonance (NMR), $\underline{(14)}$ or near-infrared spectroscopy (NIRS), (15) has been previously used to authenticate wild and farmed sea bass as well as the geographical origin. Other marine species have also been authenticated by employing stable isotope analysis (16) or coupling the stable isotope ratio with multi-element analyses, $(17)$ to assess origin and production method and even characterize the species. Biometric parameters are often used to authenticate sea bass type of production, because they are the easiest, quickest, and cheapest techniques and do not require laborious or expensive equipment or expert knowledge or specialization. (12) Elemental composition of fish flesh is generally used as a chemical signature of the particular water body where the subject has grown, because marine fish incorporate different trace elements, from the environment and the diet, into their skeletal tissues and organs. (18) The variation on elemental compositions has also been investigated in otoliths of different fish species, to distinguish wild from farmed environments; however, divergent results were obtained as a result of an interannual variability in elemental composition of otoliths, which confounded the origin determinations of subjects. (19) The use of molecular genetic markers is considered by Brown et al. the most suitable and informative tool for discrimination of wild and farmed fish, because they are not influenced by the age of the subject. (20) Unfortunately, these techniques are among the most expensive and time-consuming currently available, making them unavailable to many sectors. (19) Previous studies have assessed the capacity of different analytical techniques to distinguish wild from farmed sea bass $\underline{(10)}$ and to determine their geographical origin, (4) although these preliminary investigations examined a limited number of sources and/or subjects, sampled in a limited time span. The findings of these studies highlighted the difficulty in characterizing the farmed subjects, $(10)$ suggesting the need to introduce new variables and apply this method on a 
wide range of fish samples from various geographical locations, (4) considering the interseasonal variability for improving the robustness of the models. (10)

Prompted by all of these considerations, the present study aimed to provide a method for authentication of the origin of European sea bass specimens by combining data from a number of chemical analyses. Being one of the main European aquaculture products, European sea bass $(D$. labrax) was chosen as a result of the availability of multiple product typologies in the Mediterranean market. For the first time, a vast number of samples have been analyzed, from sources properly scattered during a 1 year sampling among the southern European area, from both aquaculture and fishery sectors; moreover, a "stocking density factor" has been introduced as a variable in the multivariate statistical analysis.

\section{Materials and Methods}

\subsection{Sampling Design}

Wild and farmed European sea bass subjects were sampled from 18 different Italian and foreign sources. Batches of 10 specimens were ordered from every source, equally split into two "macroseasons" (autumn-winter, AW; spring-summer, SS) to guarantee a perfect balance (equal number of specimens from each macroseason for each source). The geographic distribution for each sampling site is reported in Figure 1. Wild subjects $(n=45)$ came from four main areas, three in the Mediterranean Sea and one close to the French Atlantic coast. Intensively reared subjects (IR; $n=$ 85) were collected from fish farms equipped with either floating or submersible cages; in two cases, sea bass belonged to semi-intensive farms (SIR; $n=20$ ), and in a single case, they came from an extensive farm (ER; $n=10)$. Table S1 of the Supporting Information reports the respective Food and Agriculture Organization of the United Nations (FAO) fishing area, subarea, and division for each fishing site, country of origin, locality of sea bass farms, as required by Regulation (EU) 1379/2013, equipment features, and stocking density for breeding. Because the studies of Xiccato et al. (5) and Carbonara et al. (21) suggested that stocking density in production influences fish composition, an additional categorical variable was used, taking one of the following labels: "0" for wild specimens, " 1 " for extensively farmed specimens (up to $0.0025 \mathrm{~kg} \mathrm{~m}^{-3}$ ), "2" for semiintensively farmed specimens (up to $1 \mathrm{~kg} \mathrm{~m}^{-3}$ ), and " 3 " for intensively farmed specimens (up to 30 $\mathrm{kg} \mathrm{m}^{-3}$ ). Stocking density of production was recently recognized as a potential chronic stress factor in several species of fish; high density of rearing can adversely affect the quality of the farmed product, as a result of a negative effect on the fish growth rate and survival and feeding rates. $(21,22)$ Source allocation according to stocking density was based on the statements of individual farmers, through the compilation of a special form attached to every consignment. 


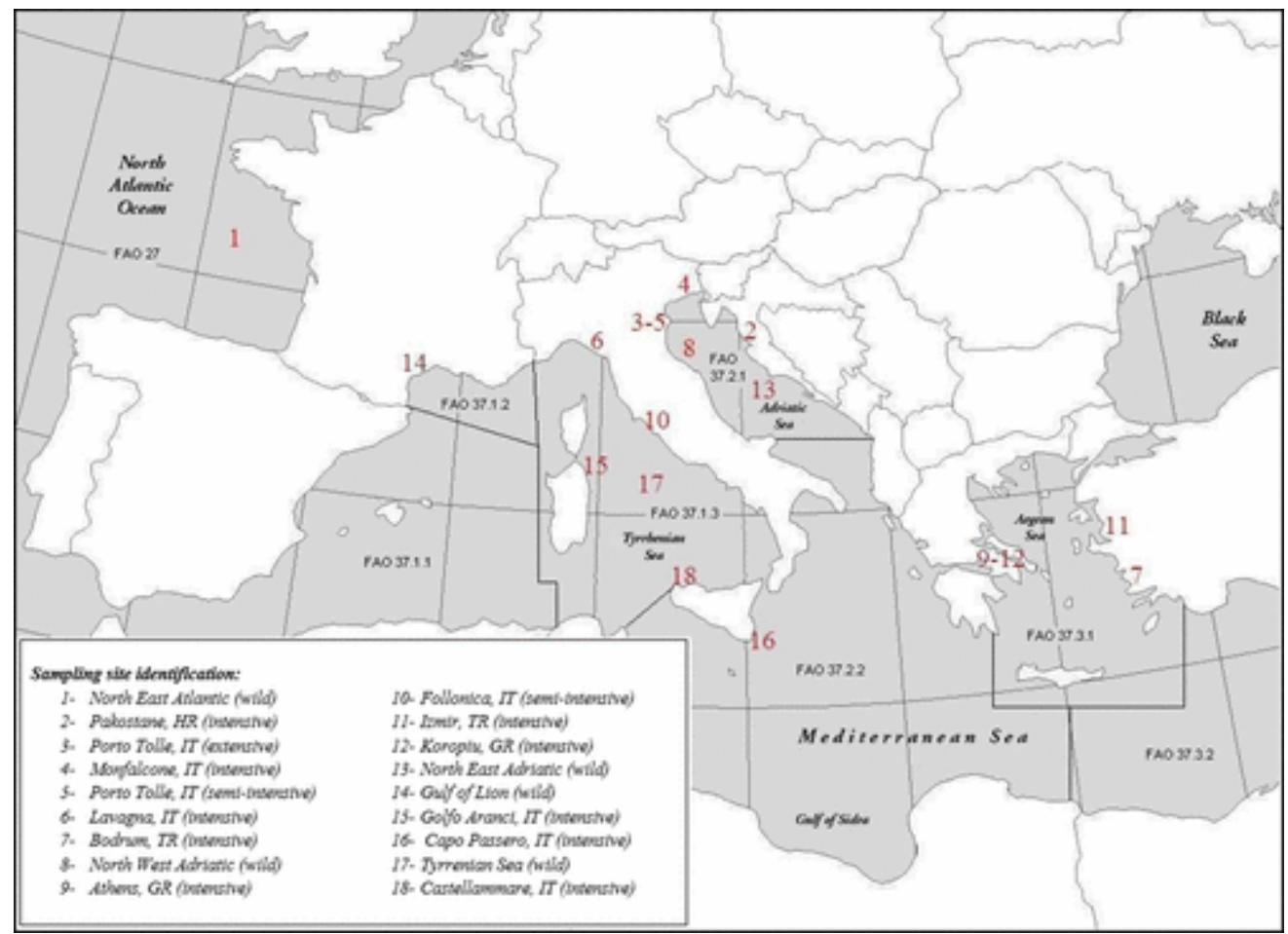

Figure 1. Geographical distribution of the sampling sites, including the pertinent FAO fishing areas, subareas, and divisions.

\subsection{Biometric Traits and Sample Preparation}

Each of 10 subjects from every batch was analyzed following the United States Environmental Protection Agency (U.S. EPA) procedure for fish sampling. (23) Every subject, after measurement of weight and length, was eviscerated, and data on the weight of eviscerated fish, viscera, liver, gonads (if any), and perivisceral fat were recorded. Wild and reared subjects, both national and foreign, were purchased from large-scale retail trade, and they were of commercial size. Fillets from each subject were homogenized by means of a food processor (Multiquick System ZK 100, Braun, Kronbergim Taunus, Germany) and quartered by hand twice; thereafter, samples were put into plastic bags, compacted, then frozen, and stored at $-20^{\circ} \mathrm{C}$. The complete description of the procedure is reported in section 2.2 of the Materials and Methods in the Supporting Information.

\subsection{Moisture Determination, Lipid Analysis, and FA Profile}

The moisture content of flesh was measured following AOAC procedure 950.46B, (25) according to which $10 \mathrm{~g}$ of homogenized flesh was put into a porcelain crucible and heated at $100-102{ }^{\circ} \mathrm{C}$ for $18 \mathrm{~h}$ to determine dry weight before calculating the moisture.

The extraction of total lipids (TL) was performed in duplicate for each sample, following a procedure proposed by Bligh and Dyer, (26) and, adopting some adjustments, briefly described as follows: around $4 \mathrm{~g}$ of homogenized fillets was put into a tube immersed in an ice bath and mixed with $18 \mathrm{~mL}$ of a solution of 1:1 chloroform/methanol for $1 \mathrm{~min}$ using an Ultra-Turrax T25 (IKAWerke GmbH \& Co., Staufen, Germany), and then $12 \mathrm{~mL}$ of a solution of 1:1 chloroform/deionized water was added to the sample and mixed. After centrifugation ( $4000 \mathrm{rpm}$ at $4{ }^{\circ} \mathrm{C}$ for $10 \mathrm{~min}$ ), the lower phase containing chloroform and dissolved TL was separated and passed through a layer of 
anhydrous sodium sulfate. A total of $1 \mathrm{~mL}$ of the lipid extract was completely desolvated on a hot plate at $50{ }^{\circ} \mathrm{C}$; the lipid residue was weighed; and the percentage of TL was calculated. Quantification of phospholipids (PL) in TL was carried out by colorimetric determination of phosphorus, following the procedure reported by Marinetti. (27) Briefly, $5 \mu \mathrm{g}$ of TL-extracted sample was mineralized with perchloric acid at $250{ }^{\circ} \mathrm{C}$. Afterward, ammonium heptamolybdate and 1-amino-2-hydroxy-4-naphthalene sulfonic acid were added to the samples; they were kept at 100 ${ }^{\circ} \mathrm{C}$ for $7 \mathrm{~min}$, until a colored complex was obtained. The absorbance of this complex was measured at $830 \mathrm{~nm}$ to estimate the amount of phosphorus in the samples; PL quantification was obtained by multiplying the calculated amount of phosphorus by 25 .

Neutral lipids (NL) were separated from PL following a normal-phase solid-phase extraction (SPE) method, described by Bayır et al., (28) which uses $12 \mathrm{~mL}$ Strata SI-1 silica (55 $\mu \mathrm{m}, 70 \AA$ ) columns, with $2 \mathrm{~g}$ of substrate (Phenomenex, Torrance, CA, U.S.A.). Briefly, after equilibration with $3 \mathrm{~mL}$ of chloroform, silica columns were loaded with the TL sample and diluted in $3 \mathrm{~mL}$ of chloroform. After that, the NL fraction was separated by charging the cartridge with $3 \mathrm{~mL}$ of chloroform 8 times. After vacuum drying of the column, PL were eluted with four aliquots of $3 \mathrm{~mL}$ of methanol and then four aliquots of $3 \mathrm{~mL}$ of a solution of 3:7 (v/v) chloroform/methanol. Fatty acid methyl esters (FAMEs) from TL, NL, and PL were obtained by transmethylation involving sulfuric acid as the catalyst, following the method proposed by Christie. (29) Briefly, samples were dried under a gentle nitrogen stream and diluted with $100 \mu \mathrm{L}$ of toluene and $1 \mathrm{~mL}$ of the methylating solution of $1 \%$ sulfuric acid in methanol (96\% purity). Samples were kept at $50{ }^{\circ} \mathrm{C}$ in a heater for $12 \mathrm{~h}$. Then, $1 \mathrm{~mL}$ of $5 \% \mathrm{NaCl}$ buffer and $900 \mu \mathrm{L}$ of hexane were added to the samples, which were successively vortex-mixed and centrifuged for $10 \mathrm{~min}$ at $2000 \mathrm{rpm}$. The supernatant containing FAME was then collected and injected into a Varian 3380 gas chromatograph (Agilent Technologies, Palo Alto, CA, U.S.A.) fitted with a CP-8200 Varian autosampler, a split injector set at $230{ }^{\circ} \mathrm{C}$, and a flame ionization detector system set at $300{ }^{\circ} \mathrm{C}$. Chromatographic separation of FAME was attained by means of a $30 \mathrm{~m} \times 0.32 \mathrm{~mm}$ (inner diameter) $\times 0.25 \mu \mathrm{m}$ (film thickness) fused silica-bonded phase column (DB-23, J\&W Scientific); the oven temperature was programmed from 150 to $230{ }^{\circ} \mathrm{C}$ at a rate of $5^{\circ} \mathrm{C} \mathrm{min}{ }^{-1}$, with a final isotherm. FAs were identified by comparing the retention times of unknown FAME to those of known FAME standard mixtures, with their content being reported as a percentage of the sum of FAME (\% FAME) of TL, NL, and PL, respectively. The complete description of the procedures for moisture determination, lipid analysis, and FA profile is reported in section 2.3 of the Materials and Methods in the Supporting Information.

\subsection{Determination of Macro- and Microelements and Toxic Elements}

Mineralization was performed by adding $6 \mathrm{~mL}$ of nitric acid (67\% purity, Ultrapure Merck, Darmstadt, Germany) and $2 \mathrm{~mL}$ of hydrogen peroxide (31\% purity, Ultrapure Merck) to $1 \mathrm{~g}$ of sample, through a MULTIWAVE 3000 microwave system (PerkinElmer). Detection of the elements was obtained by means of Optima 2100 inductively coupled plasma atomic emission spectrometry (ICP-OES, PerkinElmer, Waltham, MA, U.S.A.). For determination of the macroelements, a Meinhard cyclonic spray chamber was employed, with radial viewing configuration. Microelements and toxic elements were determined with a CETAC U5000 ultrasonic nebulizer (Thermo Fisher Scientific, Waltham, MA, U.S.A.) in axial view configuration. The complete description of the procedure is reported in section 2.4 of the Materials and Methods in the Supporting Information.

\subsection{Stable Isotope Analysis}

Determination of $\mathrm{C}$ and $\mathrm{N}$ isotopic composition in sea bass muscle was carried out through the procedure described below: $0.07 \pm 0.01$ and $0.7 \pm 0.1 \mathrm{mg}$ for $\delta^{13} \mathrm{C}$ and $\delta^{15} \mathrm{~N}$ analyses, respectively, 
of freeze-dried fillets ( $<0.6 \mathrm{~mm}$ grain size) were analyzed by means of an EA/NA-1100 elemental analyzer with CHN configuration (Thermo Finnigan), in helium continuous flow mode and coupled to a Finnigan Delta Plus XP mass spectrometer. Sample isotope ratios were then calculated according to international reference standard V-PDB for $\mathrm{C}$ and atmospheric nitrogen for $\mathrm{N}$. The complete description of the procedure is reported in section 2.5 of the Materials and Methods in the Supporting Information.

\subsection{Quality of Analytical Data}

Analyses of samples were performed in duplicate, and data were constantly monitored by means of standard reference materials (SRMs). During analysis, each SRM was processed in duplicate 3 times, following the same procedures. The accuracy and precision of the measurements, calculated on the basis of repeated analysis of SRMs, was $\pm 0.2 \%$. The descriptions of the SMRs used are reported in section 2.6 of the Materials and Methods in the Supporting Information.

\subsection{Data Processing and Statistical Analysis}

MATLAB software was used for data processing, principal component analysis (PCA), and sample classification through discriminant analysis (MATLAB "classify" function embedded into ad-hocbuilt scripts to apply cross-validation procedures and estimate classification performance).

Every source was characterized using biometric parameters and compositional characteristics of the entire sea bass fillets (as the edible part), grouped into the following sets of variables: biometric parameters, FA composition of TL, FA composition of NL, FA composition of PL, elemental composition, and isotopic abundances (Table 1). The whole set of measures, provided by each analytical technique, was statistically analyzed to obtain an "analytical signature" for every source; first of all, average, range, standard deviation, and coefficient of variation were calculated for each source. Therefore, for the automatic classification of samples, mono- and multivariate statistical analyses were employed, with the aim of predicting the production method (wild or farmed sea bass), geographical origin (FAO fishing subarea for wild subjects and country of origin for farmed subjects), and so-called "stocking density" factor.

Table 1. Description of the Sets of Variables Used To Classify Sea Bass in the Multiparametric Analysisa

\begin{tabular}{|c|c|c|c|c|c|}
\hline biometric & FA comp & A compos & A compo & elemental & isotopic \\
\hline parameter & & NL & PL & $\begin{array}{l}\text { compositi } \\
\text { on }\end{array}$ & $\begin{array}{c}\text { abundan } \\
\text { ce }\end{array}$ \\
\hline total length & moisture & N 14:0 & P 14:0 & As & $\delta^{13} \mathrm{C}$ \\
\hline body weight & $\mathrm{TL}$ & N 15:0 & P 15:0 & $\mathrm{Ca}$ & $\% \mathrm{C}$ \\
\hline $\begin{array}{l}\text { eviscerated } \\
\text { weight }\end{array}$ & $14: 0$ & N 16:0 & P 16:0 & $\mathrm{Cd}$ & $\delta^{15} \mathrm{~N}$ \\
\hline viscera weight & $15: 0$ & N 17:0 & P 17:0 & Co & $\% \mathrm{~N}$ \\
\hline liver weight & $16: 0$ & N 18:0 & P 18:0 & $\mathrm{Cr}$ & \\
\hline gonad weight & $16: 1 \omega-7$ & N 16:1 $1 \omega-7$ & P $16: 1 \omega-7$ & $\mathrm{Cu}$ & \\
\hline $\begin{array}{l}\text { perivisceral fat } \\
\text { weight }\end{array}$ & 17:0 & N $18: 1 \omega-9$ & P $18: 1 \omega-9$ & $\mathrm{Fe}$ & \\
\hline $\begin{array}{l}\text { left fillet } \\
\text { weight }\end{array}$ & 18:0 & N $18: 1 \omega-7$ & 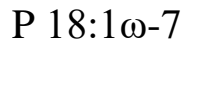 & $\mathrm{Hg}$ & \\
\hline $\begin{array}{l}\text { right fillet } \\
\text { weight }\end{array}$ & $18: 1 \omega-9$ & 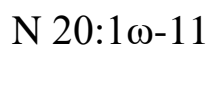 & P 20:1 & $\mathrm{K}$ & \\
\hline
\end{tabular}




\section{biometric FA composition of FA composition of FA composition of elemental isotopic parameter \\ TL \\ NL \\ PL \\ compositi abundan}

on

ce

\begin{tabular}{|c|c|c|c|}
\hline $\begin{array}{l}\text { skinned left } \\
\text { fillet weight }\end{array}$ & $18: 1 \omega-7$ & 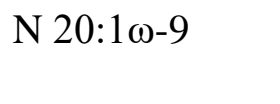 & P 22:1 \\
\hline $\begin{array}{l}\text { skinned right } \\
\text { fillet weight }\end{array}$ & $18: 2 \omega-6$ & 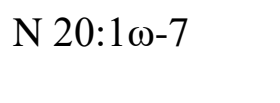 & P $18: 2 \omega-6$ \\
\hline $\begin{array}{l}\text { fillet skin } \\
\text { weight }\end{array}$ & $18: 3 \omega-3$ & 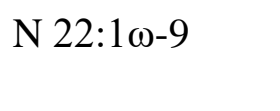 & P $20: 2 \omega-6$ \\
\hline frame weight & $18: 4 \omega-3$ & 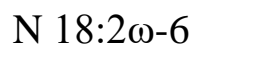 & 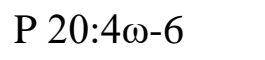 \\
\hline $\begin{array}{l}\text { condition } \\
\text { factor }\end{array}$ & $20: 1 \omega-9$ & 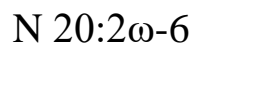 & 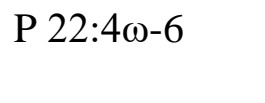 \\
\hline carcass yield & $20: 1 \omega-7$ & 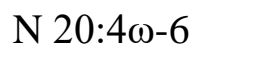 & 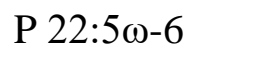 \\
\hline $\begin{array}{l}\text { viscerosomatic } \\
\text { index }\end{array}$ & $20: 2 \omega-6$ & 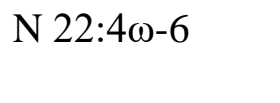 &  \\
\hline $\begin{array}{l}\text { hepatosomatic } \\
\text { index }\end{array}$ & $20: 4 \omega-6$ & 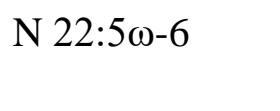 & P $18: 4 \omega-3$ \\
\hline $\begin{array}{l}\text { gonadosomatic } \\
\text { index }\end{array}$ & $20: 4 \omega-3$ & $\mathrm{~N} 18: 3 \omega-3$ & 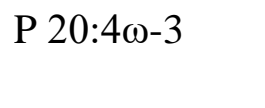 \\
\hline$\%$ fat & $20: 5 \omega-3$ &  & 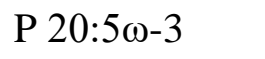 \\
\hline fillet with skin & $22: 1 \omega-11$ & 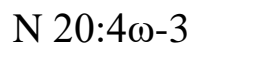 & P $22: 5 \omega-3$ \\
\hline $\begin{array}{l}\text { fillet without } \\
\text { skin }\end{array}$ & $22: 4 \omega-6$ &  & 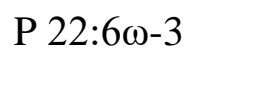 \\
\hline$\%$ frame & $22: 5 \omega-6$ & 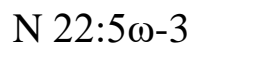 & P SFA \\
\hline$\%$ skin & $22: 5 \omega-3$ & 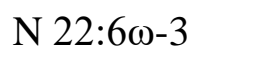 & P MUFA \\
\hline gutting yield & $22: 6 \omega-3$ & N SFA & $P \omega-6$ \\
\hline skinning yield & SFA & N MUFA & $P \omega-3$ \\
\hline \multirow{15}{*}{$\begin{array}{l}\text { skinning }+ \text { bon } \\
\text { ing yield }\end{array}$} & MUFA & N PUFA $\omega-6$ & P PUFA \\
\hline & PUFA & N PUFA $\omega-3$ & P PUFA/SFA \\
\hline & PUFA/SFA & N PUFA & P MUFA/SFA \\
\hline & MUFA/SFA & N PUFA/SFA & $P \omega-3 / \omega-6$ \\
\hline & $\omega-3$ & N MUFA/SFA & $\mathrm{P} \omega-6 / \omega-3$ \\
\hline & $\omega-6$ & $N \omega-3 / \omega-6$ & $\mathrm{P} \mathrm{EPA}+\mathrm{DHA}$ \\
\hline & $\omega-3 / \omega-6$ & $N \omega-6 / \omega-3$ & P EPA/DHA \\
\hline & $\omega-6 / \omega-3$ & N EPA + DHA & P DHA/EPA \\
\hline & $\mathrm{EPA}+\mathrm{DHA}$ & N EPA/DHA & P $20: 1+22: 1$ \\
\hline & EPA/DHA & N DHA/EPA & P ARA/EPA \\
\hline & DHA/EPA & N $20: 1+22: 1$ & P EPA/ARA \\
\hline & $20: 1+22: 1$ & N ARA/EPA & P LN/ARA \\
\hline & ARA/EPA & N EPA/ARA & P LN/ALA \\
\hline & EPA/ARA & N LA/ARA & \\
\hline & & N LA/ALA & \\
\hline
\end{tabular}


Analyses of single parameters were carried out for each classification target, to determine if different groups of subjects were significantly different from each other. To compare wild and farmed sea bass, Student's $t$ test was applied, accepting as significant $p$ values of $\leq 0.05$; to compare wild subjects from different FAO fishing subareas, farmed subjects from different countries, and sea bass classified according to stocking density, one-way analysis of variance (ANOVA) was conducted, accepting as significant $p$ values of $\leq 0.05$, plus a post-hoc Bonferroni correction as a result of the high number (175) of parameters analyzed. Multiparametric analyses (PCA and classification) were conducted on each aforementioned set of variables separately. The PCA procedure was applied to give an overview of the ability of selected parameters to discern samples according to the production method, geographical origin, and stocking density by visual inspection of the parameter space. The aim of the multivariate statistical analysis was to assess the classification performance of each set of variables and to determine an optimal and restricted parameter set for sample classification. For these purposes, samples were categorized according to the quadratic discriminant classifier. The "leave-one-out cross-validation" procedure allowed for the assessment of method robustness during classification. This validation method consists of removing from the whole sample set, one at time, every single subject, which is going to be classified on the basis of information concerning all of the other samples. (30)

\section{Results and Discussion}

Each sample was processed to collect data about biometric characteristics and chemical composition (moisture, lipid content, FA composition, macro- and microelements, and isotopic abundance). Data obtained are reported in Table S2 of the Supporting Information.

\subsection{Biometric Traits}

Weight and length of wild subjects analyzed in this study were similar to those reported in other studies. $(4,8,24)$ The condition factor is considered a good indicator of the dietary condition of fish species; (32) likewise to what was reported in other works, $(10,12,33,34)$ significant differences in condition factor and hepatosomatic index were found among subjects grouped according to the stocking density $(p<0.05)$. However, unlike the findings of Fasolato et al., $(10)$ perivisceral fat weights in cultured samples from the present study were not significantly higher than wild samples (see Table S2 of the Supporting Information). Several biometric traits measured in sea bass from this investigation were significantly different $(p<0.001)$ among subjects from different rearing systems; the diversity among groups is especially marked if comparing IR subjects to sea bass from other rearing systems (wild, ER, and SIR): weights of eviscerated samples, viscera, fillets (with and without skin), skin, and frame of IR subjects are significantly lower compared to other groups of subjects. Further parameters, such as percentages of frame, fillet and skinned fillet yields, skinned and boning yields $(p<0.001)$, liver weights, and percentages of fat and skin $(p<0.05)$ were significantly different too. ER subjects were found to be more similar to wild specimens than to farmed specimens in viscera weights and percentages of fat and skin (see Table S2 of the Supporting Information). Culture conditions are known to influence biometric traits of subjects; the feeding strategy (different feed ingredients and feeding regimes) and the stocking density (affecting swimming activity and feed intake) might influence fat deposition in liver and fillets. (4) With regard to reared subjects, significant differences were found in percentage of fat $(p<0.001)$ and perivisceral fat $(p<0.05)$, with sea bass from Turkey those with higher levels; significant differences were also found in eviscerated weights and fillet (with and without skin) weights ( $p<$ 0.05). These findings may be the results of diverse feeding strategies adopted by farmers in 
different countries; furthermore, differences in genetic strain might also be responsible (see Table $\underline{\mathrm{S} 2}$ of the Supporting Information).

\subsection{Moisture, Lipid, and FA Profile}

280 Levels of TL $(3.72 \pm 2.1 \mathrm{~g} / 100 \mathrm{~g}$ of wet weight), PL, and FA composition of wild subjects were $\mathrm{g} / 100 \mathrm{~g}$ ) was likely due to the high lipid content of subjects from source 8 , probably from commensals at a nearby intensive plant. In accordance with similar investigations, results from this study indicate that wild and farmed sea bass differ significantly for moisture content, $\underline{(8,35)}$ TL $(p<$ $0.001)$, and FA profile $(p<0.05) .(4,8,35)$ A high lipid content in the diet of IR subjects results in higher flesh fat levels; in fact, the TL content and total monounsaturated fatty acids (MUFA) are typically higher in farmed subjects, while the total saturated fatty acids (SFA), polyunsaturated fatty acids (PUFA), and $\omega-3 / \omega-6$ ratios are lower than those in wild subjects. $(4,8,10,13,35,37)$ In this study, though, MUFA was not significantly different among the production methods (see Table S2 of the Supporting Information).

Concerning PUFA, $\omega-3$ levels ( $28.86 \pm 7.47 \mathrm{~g} / 100 \mathrm{~g}$ of wet weight) in wild subjects were similar to those reported in previous studies, $\underline{(8,35,36)}$ while $\omega-6$ levels $(6.21 \pm 2.63 \mathrm{~g} / 100 \mathrm{~g}$ wet weight) were slightly lower; $(10,24,37,38)$ therefore, the $\omega-3 / \omega-6$ ratio $(5.95 \pm 3.82)$ was higher than those in the literature, representing a significantly discriminative parameter for the production method $(p<$ $0.001)$. Indeed, $\omega-3$ PUFA are generally predominant in wild sea bass, while $\omega-6$ PUFA are more abundant in farmed subjects. The increasing use of vegetable oils in feed formulation seems to depress lipogenic activity in farmed subjects and reduce flesh SFA, especially in terms of palmitic acid (16:0); in confirmation of this, a study conducted on farmed sea bass found a negative correlation between SFA and flesh TL. $(10)$ Moreover, the substitution of fish oil with vegetable

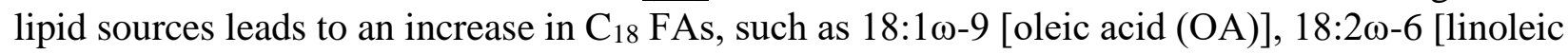

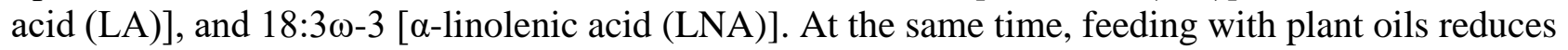

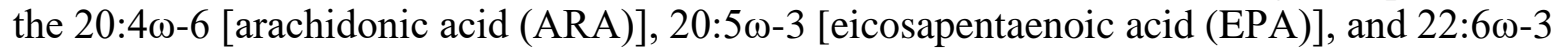
[docosahexaenoic acid (DHA)] levels in flesh. $(9,10)$ As a result of the limited capacity of marine fish to convert LA and LNA to longer chain and more unsaturated FAs, they accumulated unchanged in farmed subjects; on the other hand, as a result of the low content of ARA in commercial feed, wild sea bass are significantly richer in this FA than farmed sea bass. $\underline{(4,10,13)}$ High variability in EPA and DHA levels in wild and farmed fish has been previously observed, probably caused by diet, season, and location; (32) aquafeeds available in the market present high heterogeneity in terms of FA composition, while the FA profile of wild fish depends upon the availability of food, season, and site of catch. (12)

The TL content of fillets from SIR sea bass was higher than that from ER subjects $(9.00 \pm 2.34$ and $4.40 \pm 1.53 \mathrm{~g} / 100 \mathrm{~g}$ of wet weight, respectively), and the FA profile was similar to that for IR subjects: high in $\omega-6$ PUFA (in particular, LA), low in $\omega-3$ PUFA levels (in particular, DHA), and, consequently, with a low $\omega-3 / \omega-6$ ratio. SIR specimens were also closer to IR specimens for NL and PL composition, while ER subjects were more similar to wild subjects. The similarity in TL between ER and wild specimens was also confirmed by Orban et al.; $(35,39)$ however, in this investigation, ER subject profile was higher in SFA and MUFA, similar in $\omega-6$ PUFA, and lower in $\omega$-3 PUFA compared to findings from this study. The FA profile of SIR, instead, was in line with that reported by Trocino et al. (40) (see Table S2 of the Supporting Information).

The TL content of fillets from IR sea bass differed significantly $(p<0.001)$ among specimens from different countries as well as the profile of almost all FAs: SFA, MUFA, $\omega-6, \omega-3$, and $\omega-3 / \omega-6$ ratio. Equivalent levels of EPA and DHA were found in Italian IR as well as for Greek and Croatian farmed subjects; a predominance of the DHA content over EPA was instead detected in IR from Turkey. With regard to the FA composition of NL, Turkish IR sea bass were higher in MUFA and lower in SFA and $\omega-3$, while Italian IR were higher in $\omega-6$ compared to subjects from other 
countries. With regard to the FA composition of PL, Croatian IR sea bass showed higher levels of SFA (especially palmitic acid) compared to other countries, while fillets from Turkish IR contained higher levels in MUFA and lower levels of $\omega-3$ and $\omega-6$ (see Table S2 of the Supporting Information).

Data from the literature about IR sea bass, not distinguishing by country of origin, present wider ranges for TL (as well as in terms of SFA, MUFA, PUFA $\omega-3$, and PUFA $\omega-6$ ) and higher DHA levels than those obtained in this study. $(9,39,40)$ The NL profile of IR sea bass from this investigation was higher in terms of PUFA than those published in the literature, $(41,42)$ while the PL profile was comparable (see Table S2 of the Supporting Information).

\subsection{Trace Elements}

Elemental composition analysis showed that wild sea bass had higher levels of macro- and microelements compared to those reported in the studies of Žvab Rožič et al., Alasalvar et al., and Fuentes et al. $(6,8,13)$ Toxic elements never exceeded the limits set by the European Regulations for sea bass muscle, i.e., $0.50 \mathrm{mg} \mathrm{kg}^{-1}$ for $\mathrm{Hg}$, (43) $0.05 \mathrm{mg} \mathrm{kg}^{-1}$ for $\mathrm{Cd}, \underline{(44)}$ and $0.30 \mathrm{mg} \mathrm{kg}^{-1}$ for Pb. (45) Limits for As have not yet been regulated, but levels found in five subjects from the Atlantic source (see Figure 1) were alarming (1.07-2.30 mg kg-1 muscle). The presence of toxic elements in the environment is mainly affected by anthropogenic activities; therefore, levels of trace elements are generally lower in farmed subjects compared to wild subjects as a result of a lower age when caught and controlled feeding (46) (see Table S2 of the Supporting Information).

The elemental composition for ER subjects was similar to that for wild subjects and comparable to the data available from the literature about $\mathrm{K}, \mathrm{Ca}, \mathrm{Mg}$, and Se. (39) In comparison to those found for ER specimens analyzed by Orban et al., (39) lower levels of $\mathrm{Na}, \mathrm{P}$, and $\mathrm{Cr}$ and higher levels of $\mathrm{Zn}$ and Fe were detected as well as a minor contamination by toxic elements, becausee they found very high $\mathrm{Hg}$ concentrations as a result of environmental geological features. The elemental composition for all IR subjects was similar to those reported in the literature, $\underline{(6,13,39,46,47)}$ although no data were published on $\mathrm{S}$. The only exception was for $\mathrm{Cu}$, which was found at a higher concentration compared to the levels reported in the available literature (see Table S2 of the Supporting Information). With regard to toxic elements, very high $\mathrm{Pb}$ levels were detected in two subjects from source 2 (see Figure 1) collected in the spring/summer season (data not shown), which increased the mean above the legal limit.

Marine fish incorporate different trace elements, from the environment and the diet, into their skeletal tissues and organs, forming a chemical signature of the particular water body where the subject has grown. (18) Wild populations of sea bass from the Mediterranean move among various coastal habitats; thus, it is difficult to detect substantial differences in trace elemental signatures among wild subjects. On the contrary, aquaculture makes fish remain static in one location, and then a distinct elemental composition is likely to appear. (12) However, contrasting results have been reported within the published studies; $(8,18,46)$ feed is a factor that may explain this variability: mineral levels are extremely variable in fish feeds as a result of differences in raw ingredients used in diet formulation, the addition of specific macro- or trace mineral premixes (enriched with $\mathrm{Cu}, \mathrm{Fe}, \mathrm{Zn}, \mathrm{Mn}, \mathrm{Co}, \mathrm{Cr}$, and $\mathrm{Mg}$ ), the potential presence of contaminants in feed ingredients, (18) or the use of metal-based antifoulants to protect the cage nets. (12) Results from this study revealed that levels of $\mathrm{P}$ and Se were determinant characters for distinguishing the sea bass production method and geographical origin, $\mathrm{Na}$ and $\mathrm{Cu}$ were significantly different $(p<0.05)$ among sea bass grouped for production methods, while K and S differed significantly $(p<0.05)$ among geographical locations (see Table S2 of the Supporting Information).

\subsection{Isotopic Abundances}


Data on isotopic abundance from this study were comparable with those from the available literature; $(4,10,18,48)$ they revealed a slight difference in the ranges of $\delta^{13} \mathrm{C}$ and $\delta^{15} \mathrm{~N}$ values between wild and farmed subjects and similar levels in Italian and foreign IR sea bass (see Table S2 of the Supporting Information).

Stable isotope analysis is described to be a powerful tool in the analysis of trophic relationships in aquatic environments. $\mathrm{C}$ and $\mathrm{N}$ are the principal elements composing living organisms; they spread throughout the marine food web, enriching the isotopic signatures of marine vertebrates. The stable isotope ratio of $\mathrm{C}$ varies according to the nature of the dietary $\mathrm{C}$ sources, while stable isotopes of $\mathrm{N}$ depend upon the trophic position of the diet of the subjects. $\mathrm{CO}_{2}$ assimilated by terrestrial plants, which are major constituents of commercial feeds, is less enriched with $\delta^{13} \mathrm{C}$ than carbon sources in the natural diet of wild marine fish. As a result, the flesh of wild marine fish generally presents higher $\delta^{13} \mathrm{C}$ values than the flesh of farmed fish. The trophic level of fish feed formulations affects the $\delta^{15} \mathrm{~N}$ levels in the flesh of farmed sea bass, which may result in significant differences in $\delta^{15} \mathrm{~N}$ values in the flesh of farmed and wild sea bass, $(11)$ as reported in previous similar studies. $(4,10,15)$ According to Fasolato et al., variability in $\delta^{15} \mathrm{~N}$ seems to be more informative of the geographical origin of fish, in the case of differences in feed formulations among each area or country of provenance, rather than geological or environmental influences. Moreover, a variability in the lipid content can alter tissue $\delta^{13} \mathrm{C}$ values and may be misinterpreted as dietary or habitat shifts. $\underline{(10)}$

\subsection{Classification of European Sea Bass Sources toward Sea Bass Labeling}

Table 2 shows the results of the multivariate analysis: the percentage of subjects correctly allocated in relation to production method (farmed/wild), origin (FAO fishing subareas for wild or country of origin for farmed subjects), and stocking density, employing the selected sets of variables. For a correct implementation of the discriminant analysis for the classification of subjects, data introduced in the multivariate analysis had been scaled for fish size (considered as length), because it was found to be correlated with some of the selected set of parameters (mainly biometric parameters and elemental composition).

Table 2. Percentage of Sea Bass Correctly Classified According to Production Method, Origin (FAO Fishing Areas for Wild Specimens and Country of Origin for Farmed Specimens), and Stocking Density, Obtained by Multivariate Analysis Employing the Selected Set of Variablesa

\section{origin}

\section{set of variables production method wild farmed stocking density}

$\begin{array}{lllll}\text { biometric parameters } & 82 & 58 & 64 & 72 \\ \text { FA composition of TL 93 } & 69 & 81 & 87 \\ \text { FA composition of NL 94 } & 73 & 73 & 87 \\ \text { FA composition of PL 92 } & 64 & 92 & 92 \\ \text { elemental composition 79 } & 56 & 58 & 66 \\ \text { isotopic abundances } & 91 & 44 & 60 & 77 \\ \text { a } & & & & \end{array}$

FA, fatty acid; TL, total lipids; NL, neutral lipids; and PL, polar lipids.

FA compositions of TL, NL, and PL and isotopic abundances were the best performing sets of variables for the classification of sea bass $(n=160)$ according to production method (farmed/wild), providing percentages of correct allocation over $90 \%$. The worst performing set of variables was elemental composition, which reduced the percentage of subjects correctly classified, even for those with $100 \%$ correct allocation by other sets. Among all of the sources, number 3 (ER subjects; see 
Figure 1) had the worst performance for allocation according to production method, with subjects generally being scattered among wild sea bass.

Examining the parameter "origin", in terms of FAO fishing subareas for wild subjects $(n=45)$, the highest percentage of subjects correctly allocated was obtained by the set of variables FA composition of PL (see Table 2). All of the other sets of variables showed performances for correct allocation always below $70 \%$, with isotopic abundance having the poorest performances (44\%). With regard to farmed sea bass, once again, FA composition of PL provided the best performance for classifying subjects according to country of origin $(n=115)$, followed by FA composition of TL, while biometric parameters, isotopic abundances, and elemental composition gave a low percentage for correct allocation $(<64 \%)$. In general, farmed subjects were better classified than wild subjects by the tested set of variables.

The PCA applied for the discrimination of European sea bass according to their origin confirmed that it was impossible to obtain a clear separation of subjects based on this parameter, even when combining multiple sets of variables together. In the PCA plot for farmed subjects classified according to their country of origin (Figure 2), sea bass from Turkey were separated from the other subjects for FA composition of NL; the PCA plot for wild sea bass classified using FA composition of PL (Figure 3) showed a slight but detectable separation between subjects from Mediterranean FAO fishing subareas and those caught in the Atlantic Ocean (from source 1; see Figure 1).

\section{Figure 2}

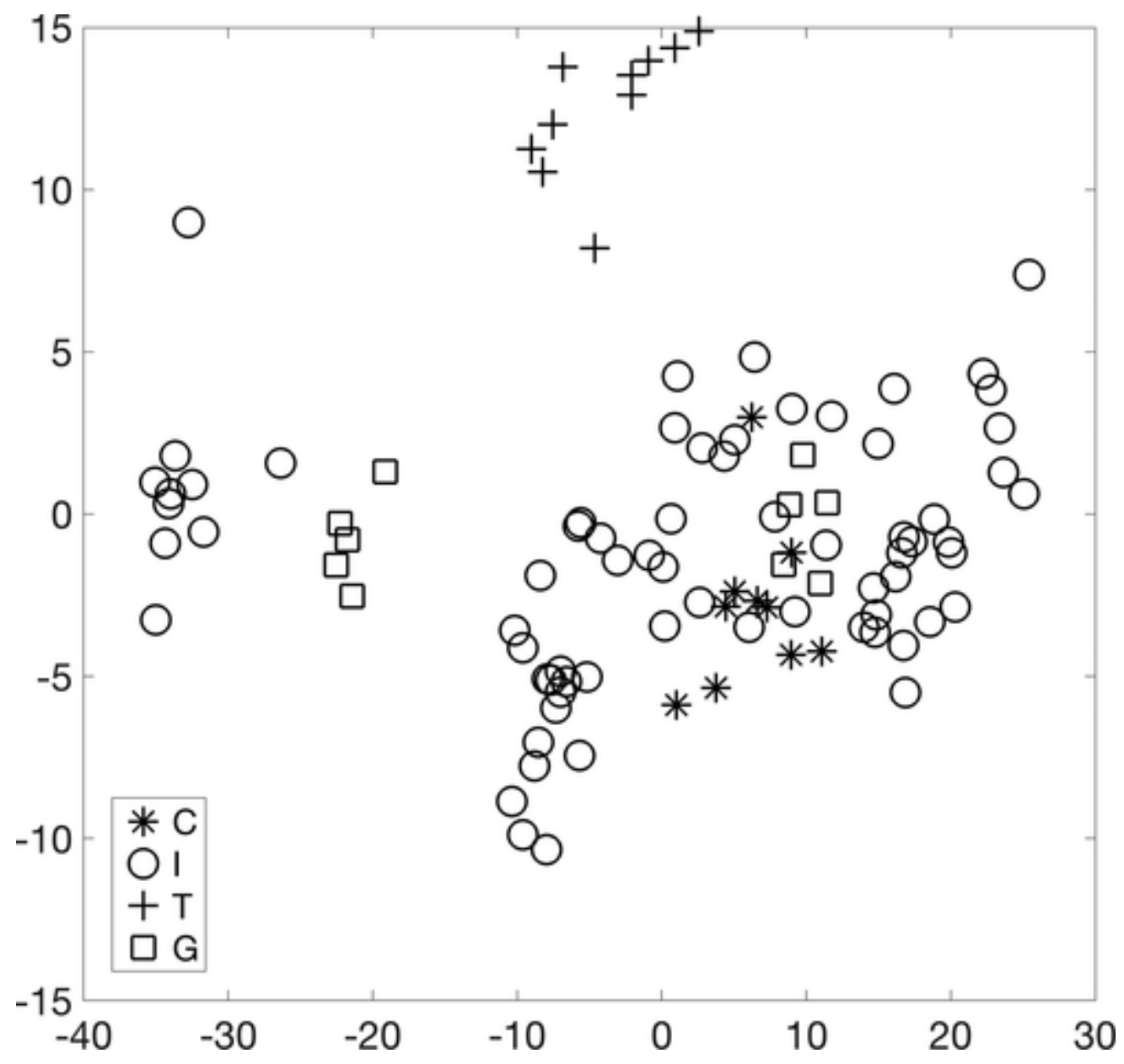

Figure 2. Scatterplot of PCA performed on farmed sea bass $(n=115)$ classified according to the country of origin and obtained using "FA composition of NL" as a set of variables. C, Croatia; I, 


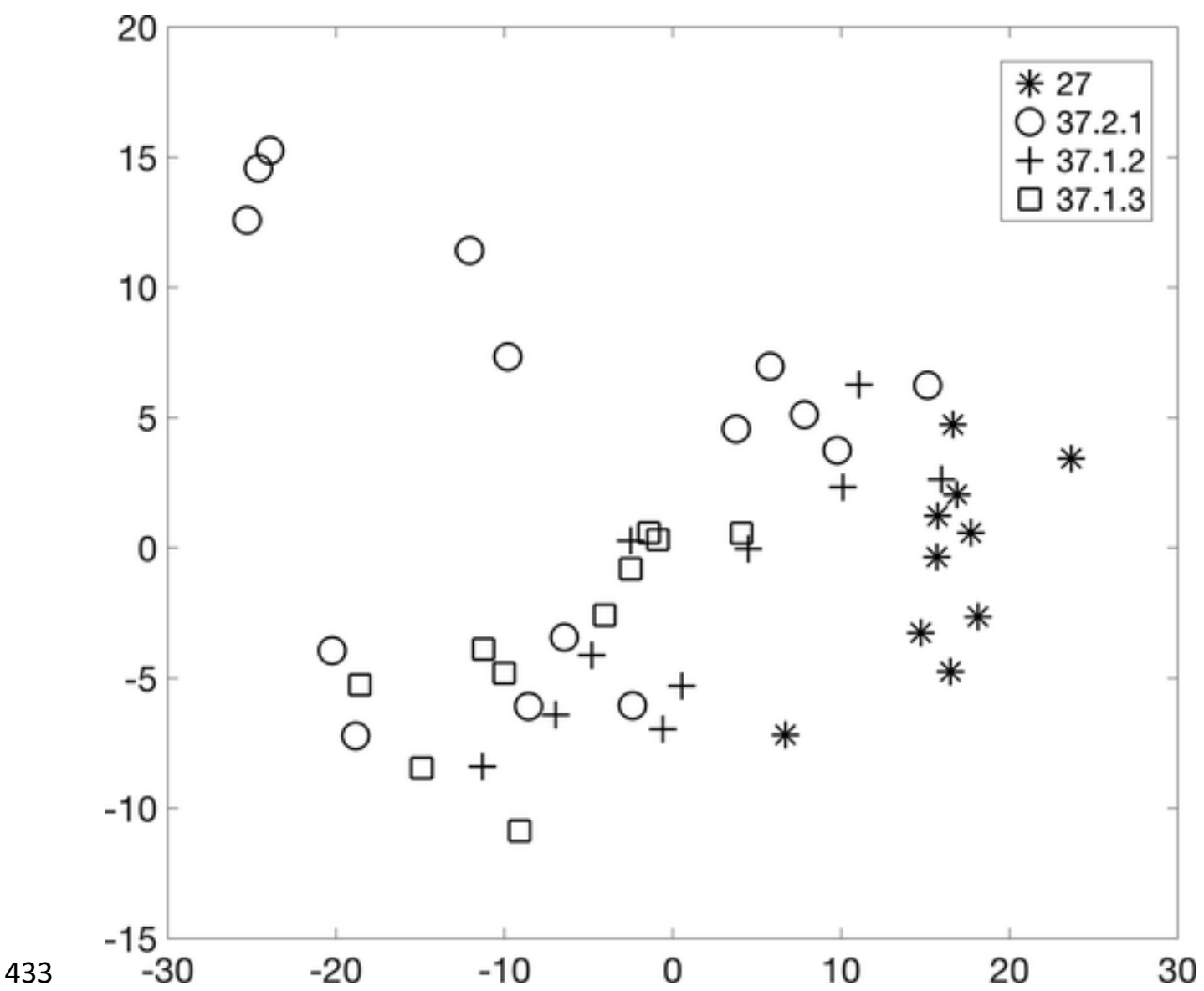

434 Figure 3. Scatterplot of PCA performed on wild sea bass $(n=45)$ classified according to FAO 435 fishing subarea of origin and obtained using "FA composition of PL" as a set of variables. FAO 436 fishing subarea 27 is in the Atlantic Ocean, the others are in the Mediterranean Sea.

437 Concerning the classification parameter "stocking density", the best performing set was FA 438 composition of PL (92\%), while FA composition of TL and NL provided slightly lower 439 percentages. Biometric parameters and isotopic abundances showed performances for correct 440 allocation around $70 \%$, and the lowest percentage was obtained by employing the elemental 441 composition set. The most evident visual separation was attained in the PCA plot (Figure 4) 442 obtained by combining three sets of variables: FA composition of TL, FA composition of PL, and 443 FA composition of NL. In this plot, the population of sea bass was separated into two big groups: 444 SIR + IR and ER + wild, with ER specimens allocated in the demarcation zone between wild and 445 SIR + IR. 


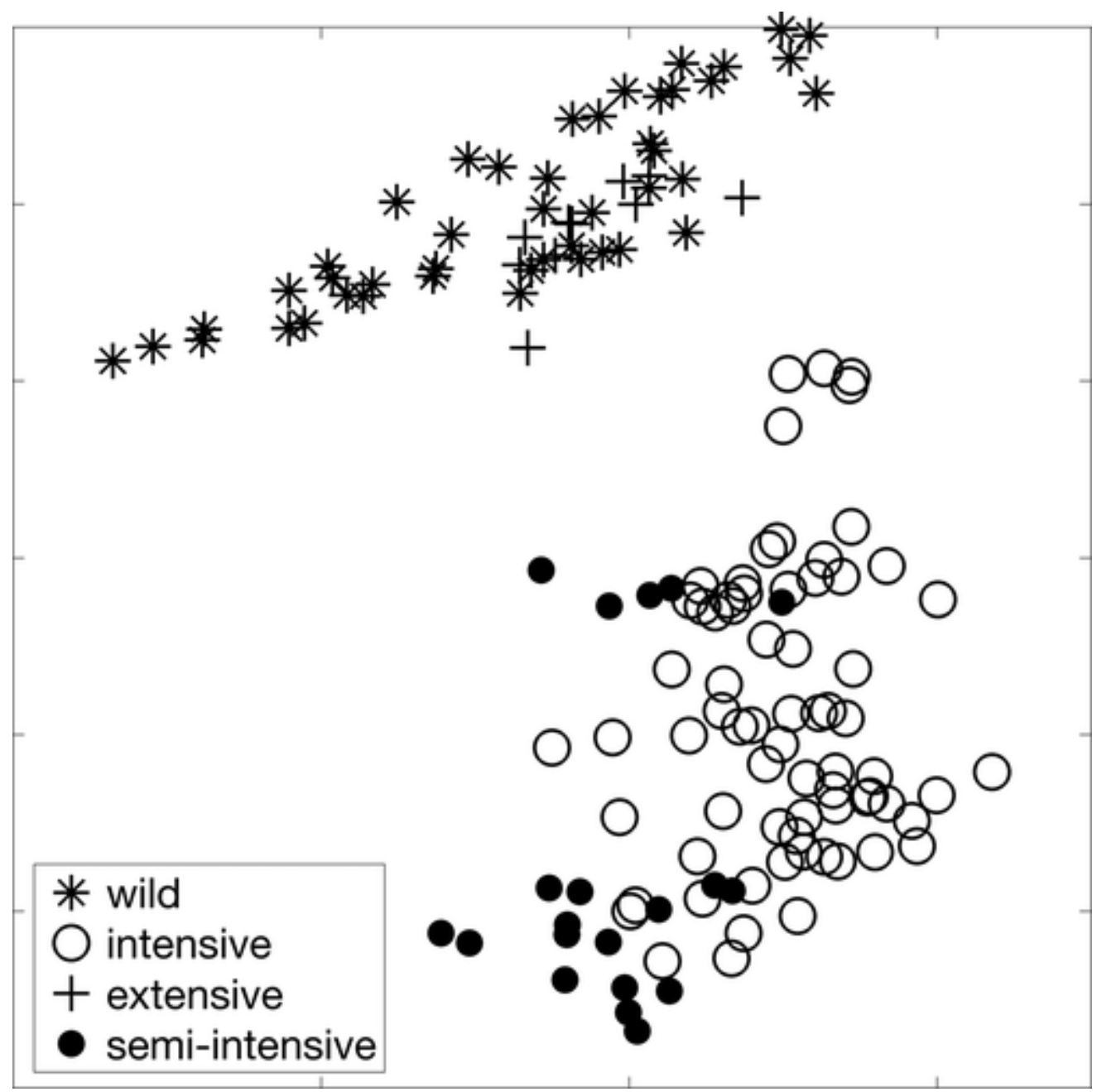

Figure 4. Scatterplot of PCA performed on 160 specimens of sea bass ( 85 from intensive rearing, 20 from semi-intensive rearing, 10 from extensive rearing, and 45 caught in the wild) and using three sets of variables: "FA composition of TL", "FA composition of PL", and "FA composition of NL".

The efficacy of FA composition for discriminating between wild and farmed fish is strongly supported by several studies; $(4,49)$ many authors have managed to classify cultured and wild European sea bass fillets on the basis of lipid profile and FA composition. $(4,8,10,13,35,37)$ According to reports in the literature, LA, LNA, ARA, and DHA generally provide the greatest contribution to the characterization of farmed and wild sea bass. (4) In fact, Fasolato et al. (10) found significantly higher levels of LA, LNA, and OA in farmed subjects, while ARA and DHA were characteristic of their wild counterparts. $(8,37)$ These results could be due to several factors, including feed type and availability, feed ingredients (usually high in fat and terrestrial plant oils, such as LA), and reduced activity of farmed fish. $(13,37)$ Moreover, because ARA, EPA, and DHA are considered to be essential for marine species, (4) high levels of these FA and low levels of LA are considered by many authors to be a specific marker for wild status. $\underline{(4,8,12,13)}$ Unlike the results reported by other authors, $(4,10)$ in this study, OA did not provide any contribution toward the characterization of farmed and wild sea bass. The FA profile represented an interesting factor to identify sea bass origin, FAO fishing subarea (for wild subjects), and country of origin (for farmed subjects), especially when focusing on PL, which provided the best performance.

Relative isotopic abundance, however, did not give such satisfying results, performing excellently in classifying the production method but not as well for other label parameters (see Table 2). 
Fasolato et al. (10) identified $\delta^{13} \mathrm{C}$ as one of the most powerful variables for describing the wild cluster. Stable isotopes of $\mathrm{C}$ and $\mathrm{N}$ are useful for differentiating among sea bass production methods $\underline{(4,10)}$ but not for distinguishing the country of origin. (13) Elemental composition obtained by means of ICP-OES was not suitable for classifying subjects according to production method, FAO fishing subarea, or country of origin. Likewise, literature data do not support the difference in mineral composition between the flesh of wild and farmed sea bass; $\underline{(8,18,46)}$ it seems that neither the origin of the fish nor the feeding system has any effect on this parameter, except for the $\mathrm{Ca}$ content. (13) Biometric parameters, despite their poor performance (see Table 2), can be considered a suitable set of variables for the authentication of the sea bass method of production as a result of the easy, rapid, and cheap data collection. (12)

In conclusion, this study examines in depth the power of analytical and biometric parameters to classify fish products according to the requirements for seafood labeling cited in Regulation (EU) 1379/2013. This is the first study conducted on a vast number of samples, collected during a 1 year sampling from multiple sources properly scattered among the central and east-southern European area, from both aquaculture and fishery sectors. Moreover, for the first time, an attempt was made to support the already-mentioned labeling criteria with stocking density, with additional voluntary information envisaged by Regulation (EU) 1379/2013.

Results from the multivariate analysis showed that good rates of correct identification of sea bass in terms of production method (farmed/wild) could be obtained using all sets of variables tested in this study. FA composition of PL is the most performing set, providing high rates of correct classification of sea bass according to the stocking density factor and the country of origin of farmed subjects. Moreover, sample classification according to stocking density, combining the three sets of variables, not only pointed out a clear separation between wild and farmed subjects but also highlighted an interesting result: the impossibility to distinguish SIR from IR subjects and ER from wild subjects (Figure 4). The simple discrimination of farmed and wild subjects may incorrectly classify ER subjects, allocating them among wild subjects. This aspect has not often been considered in similar previous studies, yet it is a key factor for correct classification of sea bass for labeling purposes. From a legislative point of view, this fact should be kept in consideration for responsible classification of sea bass, because it might induce the mislabeling of ER specimens. From a nutritional point of view, this study emphasized the ER product, highlighting its analytical similarity to wild-caught sea bass (especially for the lipid profile).

It would be interesting to carry out a sensory evaluation, to verify if the analytical and nutritional similarity between ER and wild sea bass might be sensorially noticed. Future studies may validate the findings of this study using alternative or improved chemometric methods and even extend the investigation to other fish species with a different fat content, to improve the informative value of the FA profile for fish authentication.

\section{Supporting Information}

Description of European sea bass sources (Table S1), means, standard deviations (SD), and ANOVA $p$ values of data obtained in the study (Table S2), histogram plots of Pearson's correlation coefficients of the various parameter classes with biometric parameter "length" (Figure S1), all PCA plots and loading plots grouped by set of parameters (Figures S2-S7), and extended version of the Materials and Methods

\section{Funding}

This work was supported by the Italian Ministry of Agricultural, Food and Forestry Policy (MIPAAF), under the auspices of the First Three-Year National Fisheries and Aquaculture Program (2007-2009). 
The authors declare no competing financial interest.

\section{Acknowledgments}

The authors gratefully acknowledge the contribution of the late Massimo Trentini, who both promoted and inspired this study. The authors also thank four anonymous reviewers for their helpful attitude and very constructive comments.

\section{References}

1. Thilsted, S. H.; James, D.; Toppe, J.; Iddya, K.; Subasinghe, R. Maximizing the Contribution of Fish to Human Nutrition; Food and Agriculture Organization of the United Nations (FAO): Rome, Italy, 2013; http://www.fao.org/3/a-i3963e.pdf (accessed Jan 15, 2018).

2. Carlucci, D.; Nocella, G.; De Devitiis, B.; Viscecchia, R.; Bimbo, F.; Nardone, G. Consumer purchasing behaviour towards fish and seafood products. Patterns and insights from a sample of international studies. Appetite 2015, 84, 212-227, DOI: 10.1016/j.appet.2014.10.008

3. European Union (EU). Regulation (EU) No 1379/2013 of the European Parliament and of the Council of 11 december 2013 on the common organisation of the markets in fishery and aquaculture products, amending Council Regulation (EC) n. 1184/2006 and (EC) n. 1224/2009 and repealing. Off. J. Eur. Union, L: Legis. 2013, 56, 1- 21

4. Bell, J. G.; Preston, T.; Henderson, R. J.; Strachan, F.; Bron, J. E.; Cooper, K.; Morrison, D. J. Discrimination of wild and cultured european sea bass (Dicentrarchus labrax) using chemical and isotopic analyses. J. Agric. Food Chem. 2007, 55, 5934- 5941, DOI: 10.1021/jf0704561 [ACS Full Text ACS Full Text], [CAS],

5. Xiccato, G.; Trocino, A.; Tulli, F.; Tibaldi, E. Prediction of chemical composition and origin identification of European sea bass (Dicentrarchus labrax L.) by near infrared reflectance spectroscopy (NIRS). Food Chem. 2004, 86, 275- 281, DOI: 10.1016/j.foodchem.2003.09.026

6. Žvab Rožič, P.; Dolenec, T.; Baždarić, B.; Karamarko, V.; Kniewald, G.; Dolenec, M. Element levels in cultured and wild sea bass (Dicentrarchus labrax) and gilthead sea bream (Sparus aurata) from the Adriatic Sea and potential risk assessment. Environ. Geochem. Health 2014, 36 (1), 19- 39, DOI: 10.1007/s10653-013-9516-0

7. Food and Agriculture Organization of the United Nations (FAO). Cultured Aquatic Species Information Programme, Dicentrarchus labrax; FAO: Rome, Italy, 2018; http://www.fao.org/fishery/culturedspecies/Dicentrarchus_labrax/en (accessed Jan 15, 2018).

8. Alasalvar, C.; Taylor, K. D. A.; Zubcov, E.; Shahidi, F.; Alexis, M. Differentiation of cultured and wild sea bass (Dicentrarchus labrax): total lipid content, fatty acid and trace mineral composition. Food Chem. 2002, 79, 145-150, DOI: 10.1016/S03088146(02)00122-X

9. Montero, D. T.; Robaina, L.; Caballero, M. J.; Ginés, R.; Izquierdo, M. S. Growth, feed utilization and flesh quality of European sea bass (Dicentrarchus labrax) fed diets containing 
vegetable oils: A time-course study on the effect of a re-feeding period with a $100 \%$ fish oil diet. Aquaculture 2005, 248, 121-134, DOI: 10.1016/j.aquaculture.2005.03.003

10. Fasolato, L.; Novelli, E.; Salmaso, L.; Corain, L.; Camin, F.; Perini, M.; Antonetti, P.; Balzan, S. Application of nonparametric multivariate analyses to the authentication of wild and farmed european sea bass (Dicentrarchus labrax). Results of a survey on fish sampled in the retail trade. J. Agric. Food Chem. 2010, 58, 10979- 10988, DOI: 10.1021/jf1015126 [ACS Full Text ACS Full Text],

11. Ghidini, S.; Ianieri, A.; Zanardi, E.; Conter, M.; Boschetti, T.; Iacumin, P.; Bracchi, P. G. Stable isotopes determination in food authentication: A review. Ann. Fac. Med. Vet. Univ. Parma 2006, 26, 193- 204

12. 1Arechavala-Lopez, P.; Fernandez-Jover, D.; Black, K. D.; Ladoukakis, E.; Bayle-Sempere, J. T.; Sanchez-Jerez, P.; Dempster, T. Differentiating the wild or farmed origin of Mediterranean fish: a review of tools for sea bream and sea bass. Rev. Aquac. 2013, 5, $137-$ 157, DOI: 10.1111/raq.12006

13. Fuentes, A.; Fernández-Segovia, I.; Serra, J. A.; Barat, J. M. Comparison of wild and cultured sea bass (Dicentrarchus labrax) quality. Food Chem. 2010, 119 (4), 1514-1518, DOI: 10.1016/j.foodchem.2009.09.036

14. Mannina, L.; Sobolev, A. P.; Capitani, D.; Iaffaldano, N.; Rosato, M. P.; Ragni, P.; Reale, A.; Sorrentino, E.; D'Amico, I.; Coppola, R. NMR metabolic profiling of organic and aqueous sea bass extracts: Implications in the discrimination of wild and cultured sea bass. Talanta 2008, 77, 433-444, DOI: 10.1016/j.talanta.2008.07.006 [Crossref], [PubMed], [CAS],

15. Ottavian, M.; Facco, P.; Fasolato, L.; Novelli, E.; Mirisola, M.; Perini, M.; Barolo, M. Use of near-infrared spectroscopy for fast fraud detection in seafood: Application to the authentication of wild european sea bass (Dicentrarchus labrax). J. Agric. Food Chem. 2012, 60, 639- 648, DOI: 10.1021/jf203385e [ACS Full Text ACS Full Text],

16. Kim, H.; Suresh Kumar, K.; Shin, K. H. Applicability of stable C and N isotope analysis in inferring the geographical origin and authentication of commercial fish (Mackerel, Yellow Croaker and Pollock). Food Chem. 2015, 172, 523- 527, DOI: 10.1016/j.foodchem.2014.09.058

17. Ortea, I.; Gallardo, J. M. Investigation of production method, geographical origin and species authentication in commercially relevant shrimps using stable isotope ratio and/or multi-element analyses combined with chemometrics: An exploratory analysis. Food Chem. 2015, 170, 145- 153, DOI: 10.1016/j.foodchem.2014.08.049

18. Li, L.; Boyd, C. E.; Sun, Z. Authentication of fishery and aquaculture products by multielement and stable isotope analysis. Food Chem. 2016, 194, 1238-1244, DOI: 10.1016/j.foodchem.2015.08.123

19. Arechavala-Lopez, P.; Milošević-González, M.; Sanchez-Jerez, P. Using trace elements in otoliths to discriminate between wild and farmed European sea bass (Dicentrarchus labrax L.) and Gilthead sea bream (Sparus aurata L.). Int. Aquat. Res. 2016, 8 (3), 263- 273, DOI: 10.1007/s40071-016-0142-1

20. Brown, C.; Miltiadou, D.; Tsigenopoulos, C. S. Prevalence and survival of escaped European seabass Dicentrarchus labrax in Cyprus identified using genetic markers. Aquac. Environ. Interact. 2015, 7 (1), 49- 59, DOI: 10.3354/aei00135

21. Carbonara, P.; Scolamacchia, M.; Spedicato, M. T.; Zupa, W.; Mckinley, R. S.; Lembo, G. Muscle activity as a key indicator of welfare in farmed European sea bass (Dicentrarchus labrax L. 1758). Aquacult. Res. 2015, 46, 2133-2146, DOI: 10.1111/are.12369 [Crossref], [CAS], 
22. Menezes, C.; Ruiz-Jarabo, I.; Martos-Sitcha, J. A.; Toni, C.; Salbego, J.; Becker, A.; Loro, V. L.; Martínez-Rodríguez, G.; Mancera, J. M.; Baldisserotto, B. The in fluence of stocking density and food deprivation in silver catfish (Rhamdia quelen): A metabolic and endocrine approach. Aquaculture 2015, 435, 257-264, DOI: 10.1016/j.aquaculture.2014.09.044

23. United States Environmental Protection Agency (U.S. EPA). Guidance for Assessing Chemical Contaminant Data for Use in Fish Advisories. Fish Sampling and Analysis, 3rd ed.; U.S. EPA: Washington, D.C., 2000.

24. Erdem, M. E.; Baki, B.; Samsun, S. Fatty acid and amino acid composition of cultured and wild sea bass (Dicentrarchus labrax L., 1758) from different regions in Turkey. J. Anim. Vet. Adv. 2009, 8 (10), 1959- 1963

25. McNeal, J. E. Meat and Meat Products; AOAC International: Rockville, MD, 2002.

26. Bligh, E. G.; Dyer, W. J. A rapid method of total lipid extraction and purification. Can. J. Biochem. Physiol. 1959, 37 (8), 911- 917, DOI: 10.1139/o59-099 [Crossref], [PubMed], [CAS],

27. Marinetti, G. V. Chromatographic separation, identification and analysis of phosphatides. J. Lipid Res. 1962, 3 (1), 1- 20

28. Bayır, A.; Sirkecioğlu, A. N.; Aras, N. M.; Aksakal, E.; Haliloğlu, H. I.; Bayır, M. Fatty acids of neutral and phospholipids of three endangered trout: Salmo trutta caspius Kessler, Salmo trutta labrax Pallas and Salmo trutta macrostigma Dumeril. Food Chem. 2010, 119 (3), 1050- 1056, DOI: 10.1016/j.foodchem.2009.07.064

29. Christie, W. W. Gas Chromatography and Lipids: A Practical Guide, 1st ed.; The Oily Press: Dundee, U.K., 1989.

30. Scotlandi, K.; Remondini, D.; Castellani, G.; Manara, M. C.; Nardi, F.; Cantiani, L.; Francesconi, M.; Mercuri, M.; Caccuri, A. M.; Serra, M.; Knuutila, S.; Picci, P. Overcoming resistance to conventional drugs in Ewing sarcoma and identification of molecular predictors of outcome. J. Clin. Oncol. 2009, 27 (13), 2209-2216, DOI: 10.1200/JCO.2008.19.2542 [Crossref], [PubMed], [CAS],

31. Passi, S.; Ricci, R.; Cataudella, S.; Ferrante, I.; De Simone, F.; Rastrelli, L. Fatty acid pattern, oxidation product development, and antioxidant loss in muscle tissue of rainbow trout and Dicentrarchus labrax during growth. J. Agric. Food Chem. 2004, 52 (9), 25872592, DOI: 10.1021/jf030559t [ACS Full Text ACS Full Text],

32. Grigorakis, K. Compositional and organoleptic quality of farmed and wild gilthead sea bream (Sparus aurata) and sea bass (Dicentrarchus labrax) and factors affecting it: A review. Aquaculture 2007, 272 (1-4), 55- 75, DOI: 10.1016/j.aquaculture.2007.04.062

33. Fernandes, D.; Bebianno, J. M.; Porte, C. Assessing pollutant exposure in cultured and wild sea bass (Dicentrarchus labrax) from the Iberian Peninsula. Ecotoxicology 2009, 18, $1043-$ 1050, DOI: 10.1007/s10646-009-0368-4

34. Fernandes, D.; Porte, C.; Bebianno, M. J. Chemical residues and biochemical responses in wild and cultured European sea bass (Dicentrarchus labrax L.). Environ. Res. 2007, 103 (2), 247-256, DOI: 10.1016/j.envres.2006.05.015

35. Orban, E.; Nevigato, T.; Lena, G. Di; Casini, I.; Marzetti, A. Differentiation in the lipid quality of wild and farmed seabass (Dicentrarchus labrax) and gilthead sea bream (Sparus aurata). J. Food Sci. 2003, 68 (1), 128-132, DOI: 10.1111/j.1365-2621.2003.tb14127.x

36. Vidal, N. P.; Manzanos, M. J.; Goicoechea, E.; Guillén, M. D. Quality of farmed and wild sea bass lipids studied by $1 \mathrm{H}$ NMR: Usefulness of this technique for differentiation on a qualitative and a quantitative basis. Food Chem. 2012, 135 (3), 1583-1591, DOI: 10.1016/j.foodchem.2012.06.002 
37. Lenas, D.; Chatziantoniou, S.; Nathanailides, C.; Triantafillou, D. Comparison of wild and farmed sea bass (Dicentrarchus labrax L) lipid quality. Procedia Food Sci. 2011, 1, 11391145, DOI: 10.1016/j.profoo.2011.09.170 [Crossref], [CAS],

38. Periago, M. J.; Ayala, M. D.; López-Albors, O.; Abdel, I.; Martínez, C.; García-Alcázar, A.; Ros, G.; Gil, F. Muscle cellularity and flesh quality of wild and farmed sea bass,

Dicentrarchus labrax L. Aquaculture 2005, 249 (1-4), 175- 188, DOI: 10.1016/j.aquaculture.2005.02.047

39. Orban, E.; Di Lena, G.; Nevigato, T.; Casini, I.; Santaroni, G.; Marzetti, A.; Caproni, R. Quality characteristics of sea bass intensively reared and from lagoon as affected by growth conditions and the aquatic environment. J. Food Sci. 2002, 67 (2), 542- 546, DOI: 10.1111/j.1365-2621.2002.tb10635.x

40. Trocino, A.; Xiccato, G.; Majolini, D.; Tazzoli, M.; Bertotto, D.; Pascoli, F.; Palazzi, R. Assessing the quality of organic and conventionally-farmed European sea bass (Dicentrarchus labrax). Food Chem. 2012, 131 (2), 427-433, DOI: 10.1016/j.foodchem.2011.08.082

41. Chatelier, A.; Mckenzie, D. J.; Prinet, A.; Galois, R.; Robin, J.; Zambonino, J.; Claireaux, G. Associations between tissue fatty acid composition and physiological traits of performance and metabolism in the seabass (Dicentrarchus labrax). J. Exp. Biol. 2006, 209 (17), 3429- 3439, DOI: 10.1242/jeb.02347 [Crossref], [PubMed], [CAS],

42. Skalli, A.; Robin, J. H.; Le Bayon, N.; Le Delliou, H.; Person-Le Ruyet, J. Impact of essential fatty acid deficiency and temperature on tissues' fatty acid composition of European sea bass (Dicentrarchus labrax). Aquaculture 2006, 255 (1-4), 223-232, DOI: 10.1016/j.aquaculture.2005.12.006

43. European Union (EU). Commission Regulation (EU) No 420/2011 of 29 April 2011 amending Regulation (EC) No 1881/2006 setting maximum levels for certain contaminants in foodstuffs. Off. J. Eur. Union, L: Legis. 2011, 54, 3-6

44. European Union (EU). Commission Regulation (EU) No 488/2014 of 12 May 2014 amending Regulation (EC) No 1881/2006 as regards maximum levels of cadmium in foodstuffs. Off. J. Eur. Union, L: Legis. 2014, 57, 75- 79

45. European Union (EU). Commission Regulation (EU) 2015/1005 of 25 June 2015 amending Regulation (EC) No 1881/2006 as regards maximum levels of lead in certain foodstuffs. Off. J. Eur. Union, L: Legis. 2015, 58, 9- 13

46. Custódio, P. J.; Pessanha, S.; Pereira, C.; Carvalho, M. L.; Nunes, M. L. Comparative study of elemental content in farmed and wild life Sea Bass and Gilthead Bream from four different sites by FAAS and EDXRF. Food Chem. 2011, 124, 367-372, DOI: 10.1016/j.foodchem.2010.06.020

47. Erkan, N.; Özden, Ö. Proximate composition and mineral contents in aqua cultured sea bass (Dicentrarchus labrax), sea bream (Sparus aurata) analyzed by ICP-MS. Food Chem. 2007, 102 (3), 721- 725, DOI: 10.1016/j.foodchem.2006.06.004

48. Bhouri, A. M.; Bouhlel, I.; Chouba, L.; Hammami, M.; El Cafsi, M.; Chaouch, A. Total lipid content, fatty acid and mineral compositions of muscles and liver in wild and farmed sea bass (Dicentrarchus labrax). Afr. J. Food Sci. 2010, 4 (8), 522- 530

49. Usydus, Z.; Szlifder-Richert, J.; Adamczyk, M. Variations in proximate composition and fatty acid profiles of Baltic sprat (Sprattus sprattus balticus). Food Chem. 2012, 130 (1), 97103, DOI: 10.1016/j.foodchem.2011.07.003 